\title{
Application of Automation for Low Cost Aircraft Cabin Simulator
}

\author{
CheeFai Tan ${ }^{1,2}$, Wei Chen ${ }^{1}$, Geert van den Boomen ${ }^{1}$ and Matthias Rauterberg ${ }^{1}$ \\ ${ }^{1}$ Department of Industrial Design, Eindhoven University of Technology, Eindhoven, the Netherlands \\ (Tel : +31-40-247-2514; E-mail: c.f.tan@tue.nl) \\ ${ }^{2}$ Department of Mechanical Engineering, Universiti Teknikal Malaysia Melaka, Melaka, Malaysia
}

(E-mail: cheefai@utem.edu.my)

\begin{abstract}
This paper presents an application of automation for low cost aircraft cabin simulator. The aircraft cabin simulator is a testbed that was designed for research on aircraft passenger comfort improvement product. The simulator consists of an economy class section, a business class section, a lavatory and a galley. The aircraft cabin simulator is used to simulate the general flight condition, such as taxi, take off, descending and landing. In order to simulate the aircraft flight condition, the automation technique was used to control the motion platform of the aircraft cabin simulator.
\end{abstract}

Keywords: Automation, aircraft cabin simulator, motion platform.

\section{INTRODUCTION}

Testbed is a platform on which an assortment of experimental tools and products may be deployed and allowed to interact in real-time. Successful tools and products can be identified and developed in an interactive testbed. A testbed also can be defined as an environment that is created for testing and validating purpose [1].

The aircraft cabin simulator is a testbed that was developed for European Project SEAT (Smart tEchnologies for Stress free Air Travel). The SEAT project is funded by Europeran Union that focuses on upstream questions of an integrated system in the aircraft cabin that i) creates a more healthy and more comfortable cabin environment through reduction of noise and vibrations and user specific climatic controls and ii) provides a high level of customer focused services that simulate home and office environment. The SEAT project aims to develop such new radical approach through integration of cabin systems with multimedia features.

The aircraft cabin simulator is fully designed and built in Simulation Lab, Department of Industrial Design, Eindhoven University of Technology, the Netherlands. The simulator consists of a small scale cabin-like testing platform, an inventory section, a simulation section and a control section. The interior of the aircraft cabin consists of an economy class section, a business class section, a galley and a lavatory. Each passenger seat and the lavatory are provided with a personal entertainment touch screen monitor. An inventory section is used to store the testing related equipments. A sky-like projection environment is created at the external location. In addition, the simulator is built with an innovative low-cost motion platform. The motion platform is used to simulate the flight environment such as taxi, taking off, descending and landing. The control section is fully equipped with a state of art computer systems that is used to control and monitor the simulator remotely. The aim of this paper is to describe the application of automation in simulating flight condition for the aircraft cabin simulator.

\section{CURRENT COMMERCIAL AIRCRAFT SIMULATOR}

Flight simulation is a vital part of aeronautical research. This research is conducted on a broad front, both at research establishment and in industry. Simulation ranges from comprehensive representations of the operational equipment and environment in support of full mission performance to modest simulation involving a single item of equipment or part task. Simulation allows researchers to combine real-world hardware, environmental conditions, and task demands with the ability to control events and conditions. In addition, research simulators allow designers to explore the implications of different design options without having to incur the expense and delay arising from building and testing a range of prototypes. Besides, flight simulation research has provided a means of evaluating the likely behavior and consequences arising from abnormal operating configurations without jeopardizing the safety of the flight crews. Ultimately, the use of simulation will result in data being collected faster and more economically than in the real world [2].

European project HEACE investigated in the relation between environmental parameters in cabin and cockpits as the specific work place; the subjective, medical response and performance. The investigations were conducted in simulators and mock-ups as well as in real long-haul flights. Pre-tests were carried out in the emergency trainer of Austrian Airlines in Vienna and main simulator tests are carried out in the ACE at Watford. Fig. 1 shows the emergency trainer of Austrian Airlines. The simulator experiments were carried out by BRE, Medical University Vienna, Itap $\mathrm{GmbH}$ and Oldenburg University [3]. 


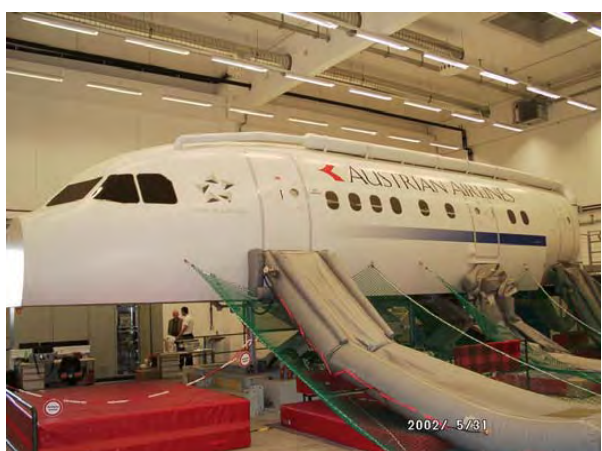

Fig. 1 Emergency trainer of Austrian Airlines [3].

United Airlines Training Centre is equipped with aircraft simulator for training purpose. The simulator is a fully operational mockup of a Boeing 747 passenger cabin. The cabin trainer and its video system has provided hands-on instruction. United Airlines uses the cabin trainer primarily for instruction in food preparation and presentation, passenger safety equipment demos and customer interaction [4].

Cranfield University houses two static aircraft cabin simulators e.g. the Large Cabin Evacuation Simulator and the Boeing 737 cabin simulator. Both simulators were used to conduct research from various aspects of cabin safety. For example, previous research examined the effectiveness of cabin crew procedures and behavior in emergencies, passenger evacuation rates under various scenarios and conditions, and passenger attention to safety information [5]. Fig. 2 shows the cabin simulator in Cranfield University.

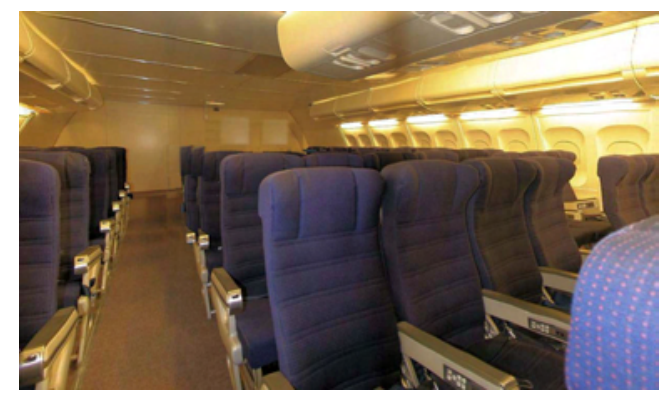

Fig. 2 The cabin simulator of Cranfild University [5].

\section{AIRCRAFT CABIN SIMULATOR}

Fig. 3 shows the arrangement of the aircraft cabin simulator from top view. The aircraft simulator included an economy class section (with two rows 3 seated economy class seat), a business class section (with a business class seat), a galley and a lavatory. The simulator was built with aluminum, wood and medium density fiber (MDF) board material. There are eight in-flight entertainment systems with touch screen function for each passenger as well as inside the lavatory. The foundation was enhanced with state of the art engineering design to withstand the dynamic impact that caused by the motion action.

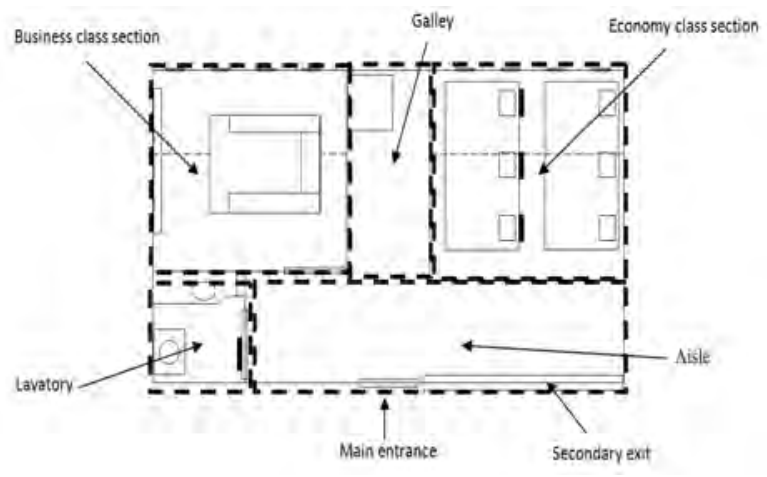

Fig. 3 Top view of aircraft cabin simulator.

The business class section as showen in Fig. 4 was equipped with a massage chair, a touch screen monitor, a high quality surround sound system and a 47 inches ambient LCD television. Two rows of economy class seat were setup and each of the seats was equipped with a touch screen monitor and a noise reduction ear phone. The seat was also embedded with a series of sensors to detect the physiological and posture of the passenger. Fig. 5 shows the snap shoot of the economy class section during a 10 hours experiment.

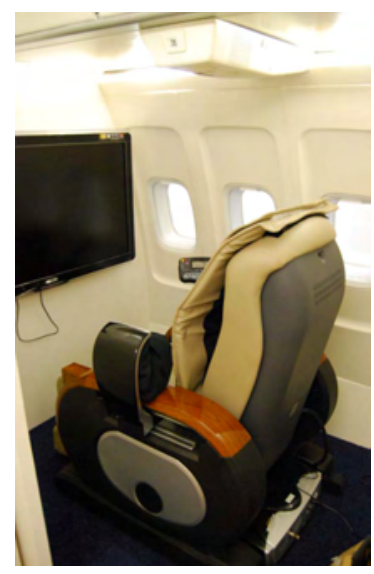

Fig. 4 Business class section.

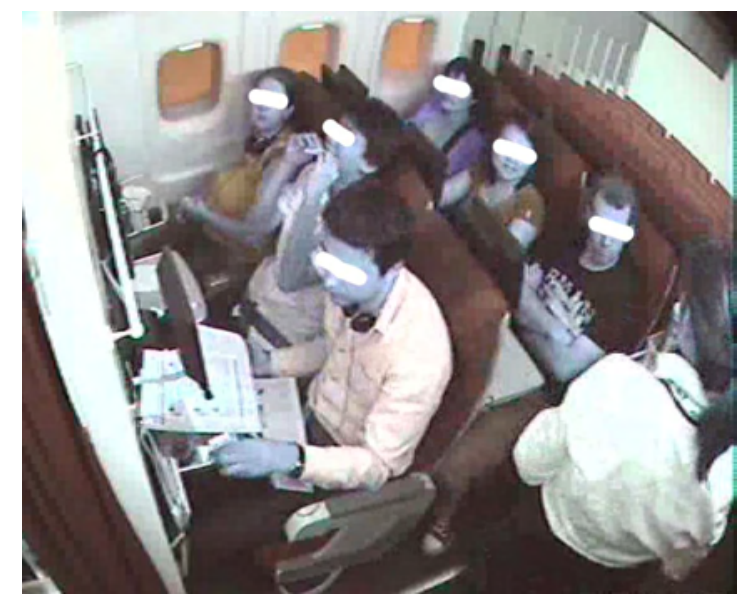

Fig. 5 Economy class section in action. 


\section{THE MOTION PLATFORM}

The motion platform is to simulate the activity of the general commercial aircraft motion. The motion platform was designed to simulate various motions such as taxing, take off, descending and landing. These motions are controlled by industrial automation device. Fig. 6 shows the external view of aircraft cabin simulator.

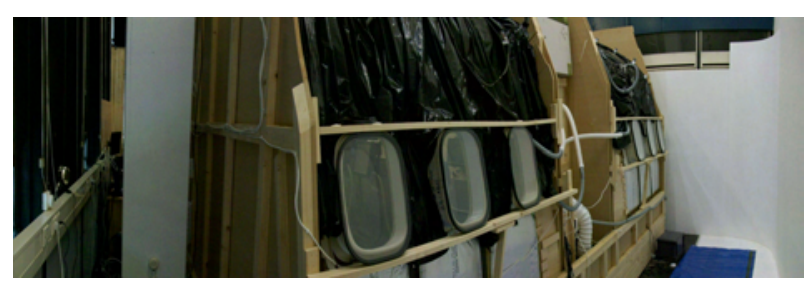

Fig. 6 The external view of the aircraft cabin simulator.

\subsection{Total design approach}

Total design approach was used in the concept development of motion platform. Different sub-functions were considered and evaluated. Subsequently, the final concept is a motion platform with four air jacks as motion devices and the programmable logic controller as reliable control device. The arrangement of air jack is shown in Fig. 7.

\begin{tabular}{|c|c|c|c|c|c|}
\hline Sult-Auncrieg & 1 & 2 & 3 & 4 & 3 \\
\hline Motian device & $\begin{array}{l}\text { Alybulice } \\
\text { clinder }\end{array}$ & $\begin{array}{l}\text { Vuwaunatic } \\
\text { cylander }\end{array}$ & Spptiale & Mectrakal jack & tar jach \\
\hline Custrel devise & Cunpulter & 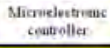 & $\begin{array}{l}\text { Fong numadile } \\
\text { logic couboiller }\end{array}$ & Shrith & Relay \\
\hline $\begin{array}{l}\text { Nomiber of motion } \\
\text { detiter }\end{array}$ & 2 & 1 & 6 & 8 & 10 \\
\hline $\begin{array}{l}\text { Mrrangerinent af } \\
\text { motion detice }\end{array}$ & $\square \square$ & П 口 & \begin{tabular}{|ll} 
& $\square$ \\
0 & 0
\end{tabular} & & \\
\hline & $\square \square$ & ㄴ & $\square$ & & \\
\hline
\end{tabular}

Fig. 7 Morphological chart of motion platform.

\subsection{The design}

The motion platform is designed to move in 5 axis $(\mathrm{X}$, $\mathrm{Y}, \mathrm{Z}, \mathrm{A}$ and B) as shown in Fig. 8. Four airbags were used as the foundation of motion platform. Each airbag can withstand $4000 \mathrm{~kg}$ of weight. The airbag is the commercial available off-road vehicle air jack.

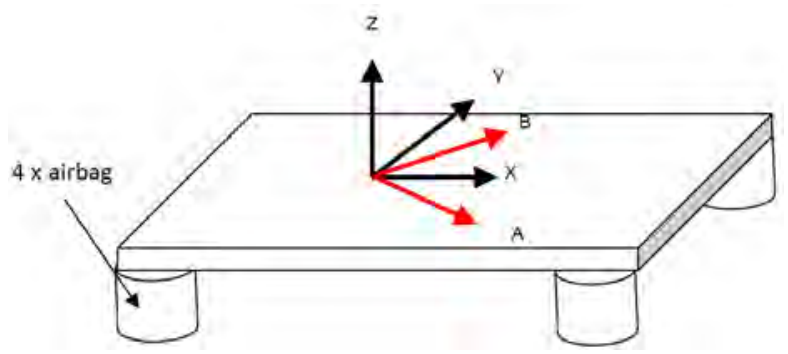

Fig. 8 The movement of motion platform.
The specification of the airbag is as shown in Fig. 9.

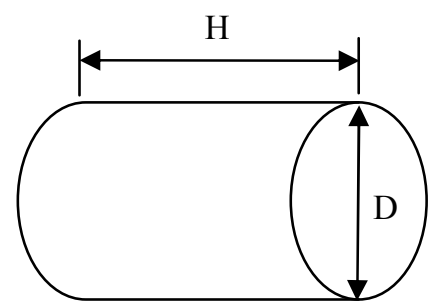

\begin{tabular}{|l|l|}
\hline Materials & Reinforced PVC \\
\hline Height, H & $750 \mathrm{~mm}$ \\
\hline Diameter, D & $600 \mathrm{~mm}$ \\
\hline Volume, V & 211.98 liter \\
\hline Capacity & $4000 \mathrm{~kg}$ \\
\hline Working pressure & $10 \mathrm{psi}(069$ bar $)$ \\
\hline
\end{tabular}

Fig. 9 The specification of airbag.

\subsection{The automation}

The industrial automation device, namely, programmable logic controller is used to control the motion of the simulator. The motion of aircraft cabin simulator can be manually controlled or automatically controlled. Fig. 10 shows the motion platform system. The compressed air cylinder with 200 bars was used to supply the air into four airbags. Four proportional solenoid air valves with air return were used to inflate and deflate the airbags. The workstation was used to update the program and monitor the motion platform.

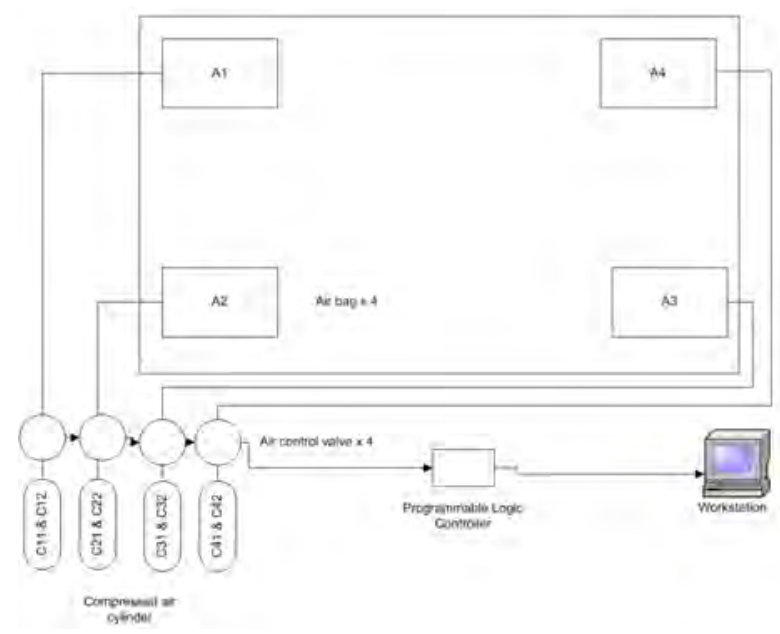

Fig. 10 The schematic of motion platform system.

\subsection{Limitation and future works}

Limitations and future works of the aircraft cabin simulator as follows:

a) The simulator was built in a room with limited space. The free movement space for simulator is small. Bigger floor space is recommended for future work.

b) The simulator was built with wood and MDF, which create gap between the connections. Thus, 
we were unable to create sound proof and pressurized environment in the simulator. The future simulator should build with sealed structure.

c) When the airbag is filled with air, the simulator is move freely. In order to solve this problem, we used L-bracket to limit the movement of simulator. We recommend the flexible joint install between simulator and floor. With this installation, the simulator will move within the specific area.

d) The airbag system was unable to create the turbulence action for the simulator. To create the turbulence action, we manually shake the simulator. In future, we can install rotary electric motor to create similar effect.

\section{CONCLUSION}

The motion platform for the aircraft cabin simulator is used to simulate the flight activities for experimental purpose. The automation technique, namely, programmable logic controller is to control the motion of the aircraft cabin simulator platform. The future application of the aircraft cabin simulator is to use for research purpose and product development purpose for aviation industry.

\section{ACKNOWLEDGEMENT}

This project is supported by the European commission DG H.3 Research, Aeronautics Unit under the $6^{\text {th }}$ Framework Programme SEAT, under contract Number: AST5-CT-2006-030958. Special thank to Ministry of Higher Education, Malaysia and Technical University of Malaysia Melaka for PhD sponsorship of first author. The authors would like to thank the following persons for their contribution: Danny Lim and Chet Bangaru.

\section{REFERENCES}

[1] UIUC Dli Glossary. 2009. http://www.mmit.stc.sh.cn/bitlibrary/papers/glossa ry.htm. Accessed on 14 May 2009.

[2] A.J. Rehmann, "A handbook of flight simulation fidelity requirements for human factors research," US Department of Transportation, Federal Aviation Administration, Technical Center, Atlantic City International Airport, USA, 1995.

[3] V. Mellert, , I. Baumann, N. Freese and R. Weber, "Impact of sound and vibration on health, travel comfort and performance of flight attendants and pilots," Aerospace Science and Technology, Vol. 12, pp. 18-25, 2008.

[4] United Airlines, Aircraft simulator at heart of united airlines training efforts. http://www.unitedvisual.com/2train/ 2tr104.asp. Accessed on 8 August 2009.

[5] Cranfield University, Aircraft cabin simulator. http:/www.cranfield.ac.uk/ soe/ facilities/ page5263. jsp. Accessed on 1 August 2009. 